\begin{tabular}{|l|l|}
\hline & \\
\hline &
\end{tabular}

RESENHA

\title{
Resenha de RUBIM, Christina de Rezende. A questão nacional e a antropologia espanhola. Curitiba: Appris, 2018. 286 p.
}

\author{
Book review: RUBIM, Christina de Rezende. A questão nacional e a antropologia \\ espanhola. Curitiba: Appris, 2018. 286 p.
}

Reseña: RUBIM, Christina de Rezende. A questão nacional e a antropologia espanhola. Curitiba: Appris, 2018. 286 p.

\section{Renata Montechiare ${ }^{1}$ \\ orcid.org/0000-0003-2466-5843 rmontechiare@gmail.com}

Recebido em: 10 dez. 2020. Aprovado em: 26 abr. 2021. Publicado em: 17 nov. 2021.

\section{(c) (1)}

Artigo está licenciado sob forma de uma licença Creative Commons Atribuição 4.0 Internacional.

\section{Apresentação}

No campo das ciências sociais, em especial da antropologia, a Espanha vive um curioso paradoxo. Trata-se de uma região com intensas distinções culturais entre suas comunidades autônomas; convive cotidianamente com idiomas variados; conta com museus e coleções etnográficas de tempos coloniais e posteriores; tem suas festas populares e celebrações como importantes marcadores culturais, compondo as listas de patrimônio da Unesco e de sítios turísticos dos mais visitados na Europa; e possui importantes e tradicionais universidades. Por que, então, sabemos tão pouco sobre a produção intelectual de seus antropólogos? Será que não existe antropologia na Espanha?

Christina de Rezende Rubim, autora de A questão nacional e a antropologia espanhola, é professora adjunta do Departamento de Sociologia e Antropologia da Faculdade de Filosofia e Ciências da Universidade Estadual Paulista Júlio de Mesquita Filho (Unesp). Defendeu a tese de livre docência em 2014 com a pesquisa sobre a questão nacional e a antropologia na Espanha. Seu livro foi publicado pela Editora Appris, em 2018, como resultado de um ciclo de pesquisas que reuniu temas centrais ao longo de sua trajetória acadêmica no Brasil, e nas duas etapas de pós-doutorado na Espanha (na Universidad de Salamanca e na Universitat Autònoma de Barcelona). Dedicada à antropologia, sua história e as questões sobre nacionalismos que a percorrem, a autora esteve presente em momentos-chave para a imersão no pulsante debate sobre autonomia, independência e identidades nacionais na Espanha e Catalunha. Aborda esta que é uma distinção fundamental para compreender o cenário que envolve as disputas em curso e a institucionalização da antropologia no país.

A pesquisa ilumina questões relevantes para aqueles interessados nas histórias da antropologia pelo mundo: existe, afinal, uma antropologia espanhola? Por que parece obscura e pouco difundida? A autora conecta 
as particularidades da disciplina antropológica no país com a história da formação da nação, em especial a partir da segunda metade do século XIX. Se tratar da história da antropologia na Espanha passa por analisar também a história do país, os embates em torno das questões nacionais não permaneceriam à margem. O tema da nação foi objeto do interesse acadêmico de Rubim ao longo das décadas e, sob a forte e confessa influência de Norbert Elias, ela se debruça sobre o conflituoso enredo que envolve as autoconsciências catalã e espanhola enquanto nação.

Esta resenha pretende apresentar ao leitor brasileiro esse livro que anima o escasso debate no país em torno da antropologia espanhola e sua invisibilidade, articulado ao tema pulsante dos nacionalismos presentes. Ao longo da constituição da antropologia no Brasil, as referências foram provenientes tanto dos países tradicionalmente hegemônicos em sua difusão de conhecimento, quanto de tradições consideradas fora do centro. No entanto, Espanha não costuma figurar entre as leituras praticadas por nossos antropólogos e antropólogas.

Adentrar a especificidade da formação dos intelectuais espanhóis passa por compreender que, no momento de consolidação da etnografia, a Espanha mergulhava em um longo e sombrio periodo de sua história recente. $\mathrm{O}$ autoritarismo interrompe a autonomia acadêmica e, com isso, a formação de antropólogos no país. Os expatriados formam-se, então, especialmente no México e nos Estados Unidos, e retornam à Espanha já em finais dos anos 1970, encontrando um país atrelado fortemente às tradições católicas fortalecidas pelo regime.

Contudo, inspirada por Eric Hobsbawn, a autora recusa-se às respostas mais homogêneas, ligadas à repressão política que envolveu a formação da disciplina, transmitidas entre as gerações de intelectuais. E apresenta um conjunto de hipóteses para explicar a condição da disciplina no país.

\section{Etnografia do conhecimento: a antropologia na Espanha}

O livro está organizado em quatro partes. A primeira delas trata do contexto teórico-prático, momento em que a autora se dedica a pensar sobre ciência e produção de conhecimento acadêmico, com o objetivo de encarar a difícil tarefa de tornar antropólogos nativos (CLIFFORD, 2008). A segunda parte trata da nação, tanto do ponto de vista de autores clássicos como Eric Hobsbawn e Benedict Anderson, quanto local, apresentando ao leitor as intrincadas disputas nacionalistas na Espanha contemporânea. A terceira parte do livro mergulha no contexto da antropologia espanhola de modo a conhecer o seu histórico e o seu repertório e investigar os relatos dos próprios antropólogos sobre sua institucionalização. Já a quarta e última parte traz os apontamentos da autora sobre a qualificação da nação e da antropologia espanhola, aprofundando suas particularidades.

Investigar o ambiente profissional da antropologia espanhola requer adentrar os espaços institucionais e instigar seus membros a analisar os caminhos percorridos por seus mestres e eles próprios. Como Geertz (1997), Peirano (1981) e Stocking Jr. (1968), na abertura do livro a autora reflete sobre a produção de uma possivel etnografia do conhecimento, ou antropologia da antropologia, ou mesmo história da antropologia.

A autora sinaliza, ao longo de toda a obra, que é Norbert Elias quem orienta, finalmente, as margens pelas quais a pesquisa percorre, do ponto de vista de uma sociologia dedicada aos processos sociais (ELIAS, 1994). Portanto, uma "antropologia dos processos de sujeitos sociais e conscientes" (RUBIN, 2018, p. 58) faz parte do horizonte o qual avista, mesmo porque a nação se inventa (HOBSBAWM, 2012) assim como inventa sua antropologia (KUPER, 1988). Desse ponto de partida conceitual, toma também Pierre Bourdieu, Benedict Anderson e Eric Hobsbawm como escolhas metodológicas. Os dois últimos especialmente para investigar a nação.

Sua pesquisa está embasada em mais de quarenta entrevistas com antropólogos e antropólogas dos principais centros de pesquisa na Espanha, em Madrid, Barcelona/Tarragona e Salamanca. Nesses diálogos, Christina Rubim buscou argumentos a respeito da constituição e do desenvolvimento da disciplina antropológica no país, considerando a recorrente percepção 
interna e externa sobre sua fragilidade, invisibilidade e até mesmo sua inexistência. Manteve-se firme na convicção de ir além das respostas mais convencionais, recorrendo à literatura histórica em busca da conexão entre nação e a centralidade da antropologia.

Encontra na sequência de episódios bélicos e ditatoriais ocorrida no país um forte e corrente argumento para a perene institucionalização desse campo do conhecimento. A consolidação da pesquisa de campo como metodologia identificadora da disciplina por excelência, entre os anos 1920 e 1930, coincidem com os duros anos do militar Miguel Primo de Rivera a frente do país, entre 1923 e 1930. A década de 1930, longe de promover a recuperação da estabilidade política, reservava à história espanhola um de seus mais sangrentos episódios: a Guerra Civil (de 1936 a 1939) levaria à ascensão do General Francisco Franco e à ditadura que durou mais de quarenta anos (de 1939 a 1975). Esse é, de fato, o enredo da narrativa dos antropólogos a respeito da dificuldade ou mesmo impedimento para a formação acadêmica em uma ciência aparentemente nova no país.

Apenas aparentemente. Nesse ponto, Christina Rubim encontra uma importante contradição: simultaneamente à marcação temporal comparativa entre a consolidação da antropologia na Europa e Estados Unidos durante os anos 1920-1930, e a história política espanhola, outros dois periodos são acionados. Em primeiro lugar, a referência à criação da antropologia como um feito espanhol, quase quatrocentos anos antes. $O$ frei Bernardino de Sahagún aparece como um dos humanistas espanhóis invocados como pai fundador da disciplina. Por volta do ano 1539 era fluente em náhuatl e conduziu seu trabalho de evangelização no México de forma concomitante à produção de manuscritos a partir da tradição oral asteca. Em segundo lugar, há a narrativa da interrupção pelo autoritarismo de um processo em curso, com a criação das cátedras em antropologia na segunda metade do século XIX, antes mesmo de Tylor em Liverpool (KUPER, 1978). Nesse percurso, a autora comenta a criação de duas importantes instituições responsáveis pela formação de antropólogos no periodo: o Museo
Nacional de Antropología de Madrid, em 1875, e a Institución Libre de Enseñanza, em 1876, também em Madrid. Tudo indica que a antropologia não era assim tão incipiente nas primeiras décadas do século XX. Rubim pergunta-se se seria, então, a repressão responsável por seu aniquilamento nos anos seguintes.

Assim como a antropologia, a nação encontra na Espanha, de acordo com a autora, o conservadorismo católico como forte mediador das visões de mundo produzidas. Ambas "vêm sendo construídas no cotidiano das universidades e dos centros de pesquisa espanholas há pelo menos um século, influenciando-se mutuamente de uma forma especial e singular" (RUBIN, 2018, p. 65). A autora dá as pistas do seu ponto de inflexão na pesquisa: o conservadorismo presente na sociedade espanhola parece ter sido definidor das escolhas efetivadas ao longo da constituição da disciplina, assim como da formação da nação. Para a autora, os ideais nacionais que atravessam as classes sociais são essenciais para compreender o pensamento antropológico, ainda mais se tratando de uma região com fortes componentes identitários como é o caso da Espanha.

Esse gancho conduz o leitor ao segundo capítulo, dedicado diligentemente à nação, tema que atravessa o pesquisador quando ocupado dos processos sociais ocorridos na Espanha nos séculos XX e XXI. A ênfase é ainda maior, como é o caso, quando se trata de pesquisa de campo realizada entre 2009 e 2015, anos que antecederam a abertura (e não conclusão) do processo de independência da Catalunha com a realização de referendos, celebrações e manifestações de massa nas ruas sobre o tema.

Retomando a história da antropologia, dessa vez conectada ao século XIX como consolidador das nações modernas, o livro discute a tríade nação-capitalismo-intelectuais por meio do recém-nascido discurso antropológico sobre as diferenças culturais, fronteiras, origens étnicas e hierarquias. A autora sublinha a conexão com o discurso evolucionista, que teve impacto profundo com a publicação de A origem das espécies, em 1859, por Charles Darwin: "No século 
XIX, a nação parecia ser a unidade natural das sociedades no mundo, a síntese do progresso, da industrialização e da modernidade. Ou seja, o ápice do processo civilizador" (2006, p. 100).

A influência das elites intelectuais, que no caso espanhol são identificadas também como clericais, enraíza uma determinada visão de mundo na medida exata em que as legitima para formular as perguntas que darão contornos à nação, ao capitalismo e à antropologia. Os três compõem um ciclo, destacando-se o papel da antropologia como produtora de sentidos para as sociedades modernas.

A autora percorre a literatura espanhola e internacional acerca da antropologia local, destacando convergências, críticas e disputas que envolvem essa construção histórica. Os argumentos passam por caminhos distintos, que muitas vezes se cruzam: da violência da repressão e da censura nos periodos autoritários, ao elitismo de uma disciplina pouco prática e voltada exclusivamente ao debate acadêmico; da perda das colônias no século XIX à dificuldade de superação do próprio provincianismo. No entanto, os efeitos da construção da nação (ou sua incompletude) e a complexidade que o tema traz parecem convergir as opiniões de parte significativa dos intelectuais apresentados no livro.

$\mathrm{Na}$ sequência, o terceiro capítulo adentra o ponto de vista nativo para recompor uma história da antropologia institucional e dar voz aos pesquisadores locais. A autora toma fôlego para apresentar ao leitor brasileiro os principais marcos históricos da construção da nação espanhola e. em particular, da Catalunha. Comenta profundas diferenças culturais, guerras, lideranças políticas, dinastias, movimentos culturais, celebrações, religiosidade, idiomas e etnias como terreno fértil para a prática etnográfica. E se pergunta: mas o que, afinal, "faltou para a construção da antropologia institucional?" (2018, p. 154). Repassa o histórico da formação dos principais centros de pesquisa, seus intelectuais e objetos de estudo, e parece não se convencer de que as ditaduras de Primo de Rivera e Francisco Franco tenham sido as únicas responsáveis por seu parco desenvolvimento. Ainda que não seja pouco, as respostas unissonas causam estranhamento.
A autora constrói a hipótese da aderência local a um pensamento com forte viés católico romano ao longo dos séculos XVIII ao XX, considerado conservador por parte dos países vizinhos, como uma marcação importante para a análise que percorre o livro. Esse pressuposto é central porque dele deriva a resposta imediata que recebeu de seus entrevistados sobre a fragilidade da antropologia produzida na Espanha, a leyenda negra, que caracteriza não apenas a antropologia, mas sua ciência e economia como um todo.

A leyenda negra aparece como um rótulo sob o qual os espanhóis seriam recorrentemente identificados. Uma profunda marca negativa atribuida por seus detratores históricos e inflamada a cada novo episódio controverso. A autora recupera sua formulação por Julián Juderias (2014), em 1914, como o amargo resquício da Espanha inquisitorial, fanática, inculta e violenta, empregado de modo difamatório até os dias de hoje. A falência da construção da disciplina antropológica no país seria, portanto, mais uma injúria.

Na última seção do livro, a autora reflete sobre sua condição na Espanha, como estudante, pesquisadora e docente, e os elos históricos de uma antropologia que da concepção colonial passa à defesa dos direitos dos pesquisados. A antropologia foi construída ao longo do século XIX, tanto do ponto de vista acadêmico quanto institucional, na esteira da formação dos Estados nacionais e da colonização. O pensamento nacionalista espanhol teve por trás as elites rurais e o clero, assinalando, portanto, um viés contrário ao liberal dos demais países europeus no período. E Christina Rubim toma esse ambiente católico conservador como a chave de análise para as escolhas conceituais e institucionais levadas a cabo na Espanha, no que se refere ao desenvolvimento da antropologia.

Nessa linha, identifica, ainda, uma relevante justificativa corrente: a perda das colônias espanholas no momento de nascimento da disciplina, essencialmente a serviço do império colonial. Como em uma conexão intrínseca entre a atividade mais pragmática da antropologia do século XIX, junto à empresa colonial, o contexto na Espa- 
nha não seria equiparável devido especialmente às independências na América.

Por fim, a autora evoca Benedict Anderson para afirmar a modernidade como uma combinação entre espaços de poder e intelectuais. Daí a antropologia institucional e sua contribuição para a construção da nação espanhola ocorrer concomitantemente à sua própria construção. Dessa vez, como um campo disciplinar dedicado a observar e desvendar as diferenças, tanto internas quanto externas, e não mais uma disciplina diretamente a serviço da colonização. Se são as elites que elaboram as análises e produzem os documentos, seu papel na promoção de heróis e anti-heróis não poderia ser minimizado na produção de narrativas sobre a nação.

Sua discussão sobre a complexidade da identidade nacional espanhola passa por destacar a forte autoconsciência das nacionalidades históricas (especialmente catalã, basca e galega), que muitas vezes se opõem ao centralismo de Madrid. O sujeito coletivo catalão (identidade-eu) e o sujeito coletivo madrilenho (identidade-nós) teriam prioridades distintas na formulação do pensamento sobre nação. Assim como Elias (1994), Rubim entende que em lugares onde há essa dupla-consciência, a desintegração torna-se fortalecida, impulsionando identidades aproximadas do cotidiano dos cidadãos, sejam elas proximidades temporais, geográficas ou políticas.

Um último e importante aporte que o livro de Christina Rubim faz é familiarizar o leitor brasileiro com referências intelectuais espanholas que poucas vezes temos a oportunidade de ver citados nos trabalhos acadêmicos aqui produzidos. José Ortega y Gasset, Julio Caro Baroja, Carmelo Lisón Tolosana, Josep Llobera i Ramon, Maria Cátedra, entre tantos outros, são mencionados, citados e contextualizados. A autora acredita que existe sim uma antropologia da Espanha, bastante particular e específica, porém não comparável porque enredada em seus processos internos.

\section{Referências}

CLIFFORD, J. Sobre a autoridade etnográfica. In: GONÇALVES, J. R. S. (ed.). A experiência etnográfica: antropologia e literatura no século XX. Rio de Janeiro: Editora UFRJ, 2008. p. 17-58.

DARWIN, C. A origem das espécies. São Paulo: Martin Claret, 2006.

ELIAS, N. O processo civilizador: uma história dos costumes. Rio de Janeiro: Jorge Zahar, 1994

GEERTZ, C. O saber local: novos ensaios em antropologia interpretativa. Petrópolis: Vozes, 1997.

HOBSBAWM, E. A invenção das tradições. Rio de Janeiro: Paz e Terra, 2012.

JUDERIAS, Julián. La leyenda negra de España. Madrid: La Esfera de los Libros, 2014

KUPER, A. Antropólogos e antropologia. Rio de Janeiro: Francisco Alves, 1978.

KUPER, A. The invention of primitive society: transformations of an illusion. London: Routledge, 1988.

PEIRANO, M. Anthropology of anthropology: the brazilian case. [S. l.]: Harvard University, 1981

STOCKING JR., G. Race, culture and evolution: essays in the history of anthropology. New York: The Free Press, 1968.

\section{Renata Montechiare}

Doutora em antropologia pela Universidade Federal do Rio de Janeiro, (UFRJ), no Rio de Janeiro, RJ, Brasil; professora da Faculdade Latino-Americana de Ciências Sociais - Sede Acadêmica Brasil (Flacso Brasil), no Rio de Janeiro, RJ, Brasil.

\section{Endereço para correspondência}

Renata Montechiare

Flacso Brasil

Rua São Francisco Xavier, 524, bloco F, $12^{\circ}$ andar, sala 12111

Maracanã, 20550-013

Rio de Janeiro, RJ, Brasil

Os textos deste artigo foram revisados pela Poá Comunicação e submetidos para validação da autora antes da publicação. 